\title{
Efeito dos probióticos no tratamento de câncer colorretal
}

\author{
Effect of probiotics in the treatment of colorretal cancer \\ Efecto de los probióticos en el tratamiento de cáncer colorretal
}

\author{
Joanne Ribeiro RODRIGUES \\ Layla Rafaele Sampaio LEARTE $^{1}$ \\ Dallyla Jennifer Morais de SOUSA ${ }^{\mathbf{1}}$ \\ Larissa Layana Cardoso de SOUSA ${ }^{1}$ \\ Yasmin de Oliveira CANTUÁRIO ${ }^{2}$ \\ Gleyson Moura dos SANTOS ${ }^{3}$
}

\begin{abstract}
${ }^{1}$ Acadêmica de Graduação, Departamento de Nutrição, Centro de Ciências da Saúde, Universidade Federal do Piauí (UFPI). 64037-085. Teresina - PI, Brasil ${ }^{2}$ Nutricionista. Pós-graduanda em Nutrição Clínica, Estética, Esportiva e Prescrição de Fitoterápicos (IPOG). 68052-450. Teresina - PI, Brasil

${ }^{3}$ Nutricionista. Mestrando em Ciências e Saúde (PPGCS/UFPI). Pós-graduando em Fitoterapia Aplicada à Nutrição (UCAM). 64085-300. Teresina-PI, Brasil
\end{abstract}

\section{Resumo}

Introdução: O câncer é definido como uma proliferação descontrolada de células malignas em um hospedeiro e considerado uma das principais causas de morte em todo o mundo. No Brasil, o câncer colorretal é a segunda causa de morte mais comum entre mulheres e a terceira mais prevalente em homens. Muitas estratégias têm sido estudadas para auxiliar o tratamento antineoplásico. Dentro desse contexto, a ingestão de probióticos, representa uma nova opção terapêutica relevante no âmbito da nutrição. Objetivo: Realizar uma revisão sobre o uso dos probióticos no tratamento de pacientes com câncer colorretal. Material e Método: Trata-se de uma revisão realizada em 2018, utilizando-se 10 artigos, pesquisados nas bases indexadas BVS e PubMed e na ferramenta de pesquisa Google acadêmico. A pesquisa incluiu artigos em português e inglês publicados no período de 2010 a 2017. Resultados: O uso de probióticos demonstrou trazer efeitos positivos ao tratamento de pacientes com câncer colorretal, trazendo benefícios como: a diminuição de enterobactérias e enterococos, melhora na modulação da imunidade local, melhora dos sintomas intestinais, recuperação da função intestinal, entre outros. Conclusão: Conclui-se que apesar dos resultados positivos observados, há a necessidade de futuros estudos de longa duração para elucidar melhor essa relação.

Descritores: Neoplasias Colorretais; Nutrientes; Probióticos.

\section{Abstract}

Introduction: Cancer is defined as an uncontrolled proliferation of malignant cells in a host and is considered a leading cause of death worldwide. In Brazil, colorectal cancer is the second most common cause of death among women and the third most prevalent in men. Many strategies have been studied to assist the antineoplastic treatment. Within this context, the ingestion of probiotics represents a new therapeutic option relevant in the field of nutrition. Objective: To review the use of probiotics in the treatment of patients with colorectal cancer. Material and method: It is a review carried out in 2018, using 10 articles, searched in the databases indexed BVS and PubMed and in the Google academic research tool. The research included articles in Portuguese and English published in the period from 2010 to 2017. Results: The use of probiotics has been shown to bring positive effects to the treatment of patients with colorectal cancer, with benefits such as: decreased enterobacteria and enterococci, improved modulation of local immunity, improvement of intestinal symptoms, recovery of intestinal function, among others. Conclusion: It is concluded that despite the positive results observed, there is a need for future long-term studies to elucidate this relationship better.

Descriptors: Colorectal Neoplasms; Nutrients; Probiotics.

\section{Resumen}

Introducción: El cáncer se define como una proliferación incontrolada de células malignas en un huésped y se considera una de las principales causas de muerte en todo el mundo. En Brasil, el cáncer colorrectal es la segunda causa de muerte más común entre mujeres y la tercera más prevalente en hombres. Muchas estrategias han sido estudiadas para auxiliar el tratamiento antineoplásico. En este contexto, la ingesta de probióticos, representa una nueva opción terapéutica relevante en el ámbito de la nutrición. Objetivo: Realizar una revisión sobre el uso de los probióticos en el tratamiento de pacientes con cáncer colorrectal. Material y método: Se trata de una revisión realizada en 2018, utilizando 10 artículos, investigados en las bases indexadas BVS y PubMed y en la herramienta de búsqueda Google académico. La investigación incluyó artículos publicados en portugués y en Inglés en el período 2010-2017. Resultados: El uso de probióticos demostró traer efectos positivos al tratamiento de pacientes con cáncer colorrectal, trayendo beneficios como: la disminución de enterobacterias y enterococos, mejora en la modulación de la inmunidad local, mejora de los síntomas intestinales, recuperación de la función intestinal, entre otros. Conclusión: Se concluye que a pesar de los resultados positivos observados, hay la necesidad de futuros estudios de larga duración para elucidar mejor esa relación.

Descriptores: Neoplasias Colorrectales; Nutrientes; Probióticos.

\section{INTRODUÇÃO}

O câncer é conceituado como uma proliferação descontrolada de células malignas em um hospedeiro e considerado uma das principais causas de morte em todo o mundo ${ }^{1}$. Com o aumento da expectativa de vida da população brasileira, as neoplasias malignas vêm se expandindo e ganhando cada vez maior importância no perfil de mortalidade do país ${ }^{2}$.

As neoplasias malignas inserem-se como a segunda causa de mortalidade na população brasileira, representando quase $17 \%$ dos óbitos de causa conhecida. Segundo dados publicados pelo Instituto Nacional do Câncer (INCA) estipulou-se que no ano de 2018, 36.360 novos casos de pacientes com diagnóstico de câncer colorretal, sendo 17.380 homens e 18.980 mulheres $^{3}$.

O câncer colorretal (CCR) é um dos tumores malignos mais comuns em homens e mulheres. A incidência mundial dessa doença é significativa, com cerca de um milhão de casos por ano. Além disso, é a causa de mais de 500.000 mortes por ano, sendo a terceira causa mais comum de mortes relacionadas ao câncer ${ }^{4}$. No Brasil, estima-se uma incidência de 34.280 novos casos ao ano e 15.415 óbitos ${ }^{5}$.

O CCR possui múltiplas origens, tendo como principais fatores de risco hereditariedade, doenças inflamatórias, idade, dieta, obesidade e sedentarismo ${ }^{6}$. Entre os fatores de risco ambientais, a dieta contribui com cerca de $35 \%$ dos novos casos. O elevado consumo de calorias, gorduras e carnes 
vermelhas associados ao baixo consumo de frutas e hortaliças pode levar a uma maior incidência da doença. Acredita-se que uma dieta variada e adequada possa prevenir de três a quatro milhões de novos casos de câncer por ano ${ }^{7}$.

Além de os fatores genéticos e ambientais desempenharem um papel importante no desenvolvimento da doença, o envolvimento de comunidades microbianas também tem sido recentemente reconhecido e relacionado ao $\mathrm{CCR}^{8}$. Segundo Gao et al. ${ }^{9}$ uma das características comuns dos fatores de risco é que todos podem causar alterações na estrutura da microbiota intestinal, levando ao desenvolvimento o CCR.

Os tratamentos comuns para o CCR são cirurgias como a colostomia, que consiste na criação cirúrgica de uma abertura (ostomia) que se insere no cólon com a finalidade de eliminar as fezes, podendo ser temporária ou permanente. Também pode ter efeitos contrários ou complicações como sepse, infecções, ventilação mecânica, fuga anastomótica, entre outros. Além do tratamento cirúrgico, é realizado de forma associada à quimioterapia ou radioterapia, o que traz mais efeitos adversos, como náuseas, êmese, diarreia e mucosite. Todos esses sintomas podem vir a afetar a condição nutricional, o equilíbrio hidroeletrolítico e a qualidade de vida do paciente $^{10}$.

O manejo nutricional desses pacientes submetidos às cirurgias é um desafio para os profissionais da nutrição. Um bom aporte nutricional pode ser importante para prevenir a desnutrição e evitar possíveis complicações advindas de diversos fatores como: efeitos colaterais do tratamento, jejum prolongado para exames e cirurgia, hábitos inadequados, alterações metabólicas e baixa ingestão alimentar geral ${ }^{11}$.

Desta forma, muitas estratégias têm sido estudadas para auxiliar o tratamento antineoplásico. Dentro desse contexto, a ingestão de probióticos, representa uma nova opção terapêutica relevante no âmbito da nutrição ${ }^{12}$.

Estudos tem mostrado que o consumo de probióticos pode promover um efeito antineoplásico em pacientes sadios, e protetor em pacientes com câncer estabelecido. Algumas evidências atentam para a possível alteração das condições físicoquímicas do colón, do metabolismo da microbiota intestinal, do aumento da produção de ácidos graxos de cadeia curta (AGCC) e do aumento de compostos antitumorais ou antimutagênicos, o que propiciaria uma melhor resposta imune e alteração da fisiologia da microbiota intestinal de forma benéfica ${ }^{13}$.

Os probióticos são organismos vivos que quando ingeridos em determinado número podem trazer benefícios ao hospedeiro, melhorando as características da microbiota intestinal. Eles inibem o crescimento de patógenos mediante a redução do $\mathrm{pH}$ intraluminal e o estímulo para a secreção de peptídeos antimicrobianos, melhoram a função de barreira da mucosa e modulam a resposta imunológica inata e adaptativa ${ }^{14}$.

É de extrema importância, portanto, o desenvolvimento de terapias auxiliadoras que possam ajudar na diminuição do desconforto no quadro clínico do paciente com CCR. O uso de probióticos pode permitir que os pacientes tenham a diminuição dos sintomas, evitando diversas infecções bacterianas, prevenindo e reduzindo a incidência e severidade da diarreia, recuperando mais rapidamente a função intestinal e melhorando a resposta ao estresse sistêmico e da imunidade sistêmica ${ }^{8}$.

Nesse contexto, o objetivo do presente trabalho foi realizar uma revisão com base na literatura, para avaliar o uso dos probióticos, no tratamento de pacientes com câncer colorretal.

\section{MATERIAL E MÉTODO}

Trata-se de um estudo de revisão sistemática. Para identificar os artigos acerca do assunto, realizou-se busca nas bases indexadas BVS e SCIELO e na ferramenta de pesquisa Google acadêmico, de junho a julho de 2018, com a seguinte estratégia de busca: "Câncer Colorretal", "Suplementação" e "Microbiota". Foram utilizados termos em português e inglês. Realizou-se também buscas manuais nas referências utilizadas na lista de referências bibliográficas dos artigos encontrados.

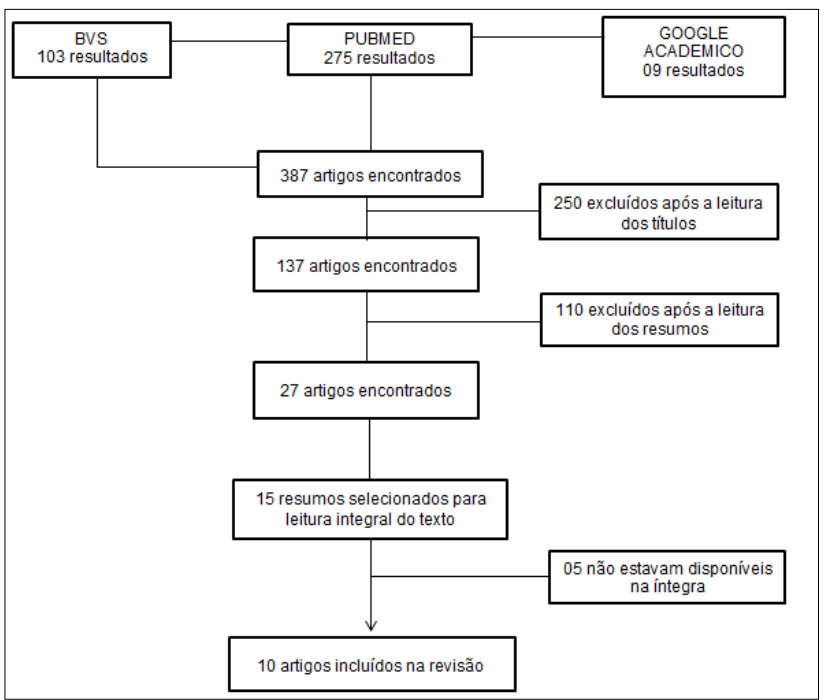

Figura 1: Fluxograma de identificação e seleção dos artigos para revisão sistemática sobre o uso dos probióticos no tratamento de pacientes com câncer colorretal.

Fonte: Dados da Pesquisa (2018)

Para a inclusão dos artigos, foram empregados os seguintes critérios: estudos cujo objetivo se tratava diretamente sobre o escopo deste trabalho, com metodologia claramente descrita, publicados em periódicos na língua inglesa ou portuguesa no período de 2010 a 2017, com textos disponíveis na íntegra. Foram excluídos estudos cujo desfecho não se tratava diretamente sobre o tema 
deste trabalho. Após a consulta às bases de dados e a aplicação das estratégias de busca, foram feitas leituras dos títulos dos artigos de forma a identificar aqueles estudos que apresentavam conformidade com a temática trabalhada. Em seguida, foram lidos todos os resumos resultantes. Nos casos em que a leitura do resumo era suficiente, os artigos eram selecionados e então obtidos a versão integral para confirmação de elegibilidade e inclusão no estudo (Figura 1). A análise dos estudos encontrados foi feita de forma descritiva.

\section{RESULTADOS}

Os dados extraídos dos estudos foram tabulados segundo autor, ano, objetivo, metodologia e resultados (Quadro 1).

Quadro 1. Características dos estudos sobre o uso dos probióticos no tratamento de pacientes com câncer colorretal

\begin{tabular}{|c|c|c|c|}
\hline Autor/Ano & Objetivo & Metodologia & Resultados \\
\hline $\begin{array}{c}\text { Gao et al9 } \\
2015\end{array}$ & $\begin{array}{lr}\text { Avaliar } & \text { a } \\
\text { confiabilidade } & \text { dos } \\
\text { probióticos } & \text { orais } \\
\text { perioperatórios } & \text { na } \\
\text { alteração } & \text { da } \\
\text { composição } & \\
\text { microbiana } & \text { do } \\
\text { intestino e melhora } \\
\text { microecológica em } \\
\text { pacientes com CCR } \\
\end{array}$ & $\begin{array}{lr}\text { Avaliaram } & 22 \\
\text { pacientes, no qual, } \\
\text { foram randomizados e } \\
\text { divididos em dois } \\
\text { tratamentos: o grupo } \\
\text { CGT }(\mathrm{n}=11) \text { recebeu } \\
\text { perioperatório oo } \\
\text { placebos e o grupo } \\
\text { PGT (n = } 11) \\
\text { receberam probióticos }\end{array}$ & $\begin{array}{l}\text { Os probióticos foram } \\
\text { confiáveis para alterar a } \\
\text { composição, a riqueza e a } \\
\text { diversidade r da } \\
\text { microbiota intestinal, } \\
\text { além de inibir potenciais } \\
\text { agentes patogênicos e } \\
\text { aumentaram o número de } \\
\text { certos microrganismos } \\
\text { benéficos }\end{array}$ \\
\hline $\begin{array}{l}\text { Zhang et } \\
\text { al. }{ }^{15} \\
2012\end{array}$ & 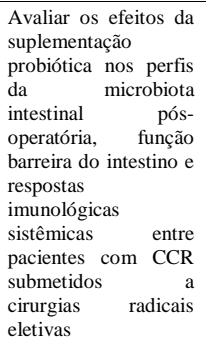 & 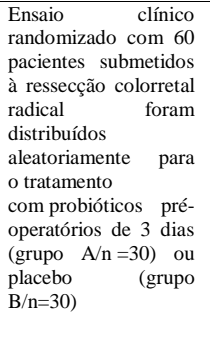 & $\begin{array}{l}\text { Probióticos minimizaram } \\
\text { a ocorrência de } \\
\text { complicações pós- } \\
\text { operatória infecciosas, } \\
\text { com possíveis } \\
\text { mecanismos atribuídos à } \\
\text { manutenção inda da } \\
\text { microbiota intestinal e } \\
\text { restrição da translocação } \\
\text { bacteriana do intestino }\end{array}$ \\
\hline $\begin{array}{c}\text { Liu et al. }^{16} \\
2011\end{array}$ & $\begin{array}{l}\text { Determinar os efeitos } \\
\text { da administração } \\
\text { perioperatória de } \\
\text { probióticos na função } \\
\text { de barreira intestinal e } \\
\text { no desfecho cirúrgico } \\
\text { em pacientes } \\
\text { submetidos à cirurgia } \\
\text { colorretal eletiva }\end{array}$ & $\begin{array}{l}\text { Ensaio } \text { clínico } \\
\text { randomizado, } \\
\text { utilizando-se } 100 \\
\text { pacientes, sendo } 50 \\
\text { para grupo controle e } \\
50 \text { para grupo com } \\
\text { probióticos. Os } \\
\text { antibióticos foram } \\
\text { administrados durante } \\
6 \text { dias no pré- } \\
\text { operatório e } 10 \text { dias } \\
\text { no pós-operatório }\end{array}$ & $\begin{array}{l}\text { O grupo de probióticos } \\
\text { aumentou a resistência } \\
\text { transpitelial, diminui a } \\
\text { permeação intestinal de } \\
\text { agentes patogênicos, } \\
\text { diminui a translocação } \\
\text { bacteriana } \\
\text { enteroptogênica, } \\
\text { melhorou o peristaltismo, } \\
\text { a incidência de diarreia } \\
\text { infecciosa } \\
\text { complicações diversas }\end{array}$ \\
\hline $\begin{array}{c}\text { Yongzhi et } \\
\text { al. }{ }^{17} \\
2016\end{array}$ & 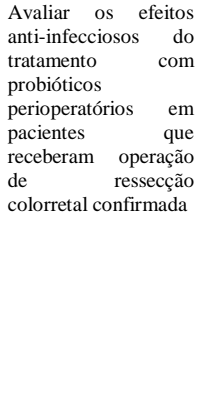 & $\begin{array}{lr}\text { Estudo duplo cego } \\
\text { randomizado } \\
\text { controlado por } \\
\text { placebo. Participaram } \\
\text { do estudo } 79 \\
\text { pacientes r com } \\
\text { diagnóstico de câncer } \\
\text { colorretal esporádico, } \\
\text { aleatoriamente } \\
\text { designados para } \\
\text { grupo controle (n = } \\
\text { 37) ou probióticos (n } \\
=42), \text { os quais } \\
\text { receberam probióticos } \\
\text { ou placebo de } \\
\text { tratamento, durante } \\
12 \text { dias consecutivos }\end{array}$ & $\begin{array}{lr}\text { Nos } & \text { pacientes } \\
\text { submetidos à ressecção, a } \\
\text { administração } \\
\text { probióticos de } \\
\text { operatório influenciou } \\
\text { significativamente } \\
\text { recuperação da função } \\
\text { intestinal, e essa melhoria } \\
\text { pode ser de importante } \\
\text { significado clínico na } \\
\text { redução } \\
\text { complicações infecciosas } \\
\text { de curto prazo, tais como } \\
\text { bacteremia }\end{array}$ \\
\hline $\begin{array}{c}\text { Kotzampassi } \\
\text { et al. }{ }^{18} \\
2015\end{array}$ & $\begin{array}{l}\text { Investigar o impacto } \\
\text { de uma preparação de } \\
\text { quatro probióticos } \\
\text { sobre a morbidade } \\
\text { pós operatória após } \\
\text { cirurgia do cólon. } \\
\text { Avaliou o efeito da } \\
\text { alimentação r com } \\
\text { probióticos r na } \\
\text { expressão de genes } \\
\text { que regulam a } \\
\text { produção } \\
\text { citoquinas de }\end{array}$ & $\begin{array}{l}\text { Estudo randomizado } \\
\text { duplo-cego, } \\
\text { controlado por } \\
\text { placebo, realizado } \\
\text { recrutando pacientes } \\
\text { (n=164) submetidos à } \\
\text { cirurgia de câncer } \\
\text { colorretal. O placebo } \\
\text { ou uma formulação } \\
\text { de } L \text { acidophilus, } L \text {. } \\
\text { plantarum, } B . \\
\text { lactise } S \text {. } \\
\text { boulardii foram } \\
\text { administrados } 1 \text { dia } \\
\text { antes da operação e } \\
\text { continuando durante } \\
15 \text { dias após a } \\
\text { operação }\end{array}$ & $\begin{array}{l}\text { A ingestão da formulação } \\
\text { iniciando um dia antes da } \\
\text { cirurgia colorretal e } \\
\text { continuando por } 15 \text { dias } \\
\text { pós-operatório causou } \\
\text { significativa diminuição } \\
\text { do risco de complicações } \\
\text { pós-operatórias, } \\
\text { ventilação mecânica, } \\
\text { infecções e vazamento } \\
\text { anastomose }\end{array}$ \\
\hline
\end{tabular}

Quadro 1. Continuação

\begin{tabular}{|c|c|c|c|}
\hline Autor/Ano & $\begin{array}{l}\text { Objetivo } \\
\end{array}$ & Metodologia & $\begin{array}{l}\text { Resultados } \\
\end{array}$ \\
\hline $\begin{array}{c}\text { Lee et al. }{ }^{19} \\
2014\end{array}$ & \begin{tabular}{lr}
\multicolumn{3}{l}{ Investigar os efeitos } \\
de 12 semanas & de \\
administração & de \\
probióticos & em \\
pacientes com câncer \\
colorretal
\end{tabular} & $\begin{array}{l}\text { Ensaio duplo-cego, } \\
\text { randomizado } \\
\text { controlado por } \\
\text { placebo. Grupo } \\
\text { probióticos }(\mathrm{n}=28) \text { e } \\
\text { grupo placebo }(\mathrm{n}=32) \\
\text { duas vezes ao dia } \\
\text { durante } 12 \text { semanas }\end{array}$ & $\begin{array}{l}\text { Os probióticos } \\
\text { melhoraram os sintomas } \\
\text { intestinais e a qualidade } \\
\text { de vida em sobreviventes } \\
\text { de câncer colorretal }\end{array}$ \\
\hline $\begin{array}{c}\text { Gianotti et } \\
\text { al. }^{20} \\
2010\end{array}$ & 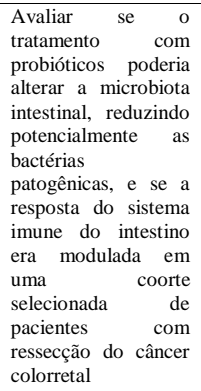 & $\begin{array}{l}\text { Ensaio clínico } \\
\text { randomizado, duplo- } \\
\text { cego, tendo por } \\
\text { amostra um número } \\
\text { de 31 pacientes. } \\
\text { Foram utilizados } \\
\text { grupos placebo e do } \\
\text { uso de probióticos, } \\
\text { sendo avaliados no } \\
\text { pós-operatório do } 2^{\circ} \\
\text { ao } 4^{\circ} \text { dia }\end{array}$ & $\begin{array}{l}\text { A administração de doses } \\
\text { mais elevadas } \\
\text { possibilitou uma redução } \\
\text { na contagem } \\
\text { enterobactérias } \\
\text { enterococos, reduzindo } \\
\text { dessa maneira a a } \\
\text { concentração de agentes } \\
\text { patogênicose aumento na } \\
\text { modulação da imunidade } \\
\text { local }\end{array}$ \\
\hline $\begin{array}{l}\text { Stephens e } \\
\text { Hewett }^{21} \\
2012\end{array}$ & $\begin{array}{l}\text { Avaliar a eficácia de } \\
\text { um probiótico, } \\
\text { VSL\#3 na melhoria } \\
\text { da função intestinal } \\
\text { após o fechamento } \\
\text { de ileostomia }\end{array}$ & $\begin{array}{l}\text { Estudo randomizado } \\
\text { prospectivo, duplo- } \\
\text { cego, controlado por } \\
\text { placebo, de uma } \\
\text { preparação probiótica. } \\
\text { Sessenta e três } \\
\text { pacientes que se } \\
\text { submeteram a uma } \\
\text { ileostomia reversa } \\
\text { foram randomizados } \\
\text { para receber } \\
\text { tratamento de } 4 \\
\text { semanas de terapia } \\
\text { probiótica }(n=31) \text { ou } \\
\text { placebo }(n=32) \\
\end{array}$ & $\begin{array}{l}\text { Verificou-se que o } \\
\text { probiótico VSL\# } 3 \text { foi } \\
\text { ineficaz na prevenção ou } \\
\text { redução dos sintomas } \\
\text { intestinais desordenados } \\
\text { pós-operatórios } \\
\text { associados à síndrome de } \\
\text { ressecção anterior em } \\
\text { pacientes que sofreram a } \\
\text { reversão de uma } \\
\text { ileostomia em alça }\end{array}$ \\
\hline $\begin{array}{c}\text { Xia et al. }{ }^{22} \\
2010\end{array}$ & $\begin{array}{l}\text { Estudar o efeito da } \\
\text { preparação intestinal } \\
\text { com probióticos na } \\
\text { função de barreira } \\
\text { intestinal após } \\
\text { cirurgia para câncer } \\
\text { colorretal }\end{array}$ & $\begin{array}{l}\text { Teste controlado e } \\
\text { aleatório, do tipo } \\
\text { randomizado. } \\
\text { Utilizando-se um total } \\
\text { de } 60 \text { pacientes, em } \\
\text { dois grupos: controle } \\
\text { e teste. A preparação } \\
\text { intestinal de um dos } \\
\text { probióticos foi } \\
\text { administrada no grupo } \\
\text { teste e a convencional } \\
\text { no controle }\end{array}$ & $\begin{array}{l}\text { Foram obtidas boas e } \\
\text { excelentes preparações } \\
\text { intestinais em } 88 \% \text { no } \\
\text { grupo experimental e } \\
92 \% \text { no grupo controle (P } \\
=0,072 \text { ) Os níveis de } \\
\text { expressão de occludina e } \\
\text { IgA de cólon foram } \\
\text { significativamente } \\
\text { maiores no grupo de teste } \\
\text { em comparação com os } \\
\text { do grupo controle. O } \\
\text { número de pacientes com } \\
\text { PCR positivo no grupo } \\
\text { experimental roi } \\
\text { significativamente menor } \\
\text { do que o grupo controle } \\
\text { após a operação. Não } \\
\text { houve diferenças } \\
\text { significativas nas nas } \\
\text { complicações entre os } \\
\text { dois grupos as a }\end{array}$ \\
\hline $\begin{array}{c}\text { Zhu et al. }{ }^{23} \\
2012\end{array}$ & $\begin{array}{l}\text { Investigar o efeito da } \\
\text { aplicação } \\
\text { perioperatória de } \\
\text { probióticos } \\
\text { intestinais para } \\
\text { substituir agentes } \\
\text { antimicrobianos } \\
\text { intestinais orais na } \\
\text { biota intestinal e } \\
\text { função imune em } \\
\text { pacientes cirúrgicos } \\
\text { com câncer } \\
\text { colorretal. }\end{array}$ & $\begin{array}{l}60 \text { pacientes com } \\
\text { câncer colorretal } \\
\text { submetidos à cirurgia } \\
\text { radical laparoscópica } \\
\text { eletiva roram } \\
\text { randomizados para } \\
\text { receber a preparação } \\
\text { do intestino pré- } \\
\text { operatório usando } \\
\text { agentes } \\
\text { antimicrobianos } \\
\text { intestinais orais (n = } \\
20 \text { ou usando } \\
\text { probióticos intestinais } \\
\text { orais desde o quinto } \\
\text { dia antes da operação } \\
\text { e às } 24 \text { h após a } \\
\text { operação por } 7 \text { dias } \\
\text { consecutivos. }\end{array}$ & 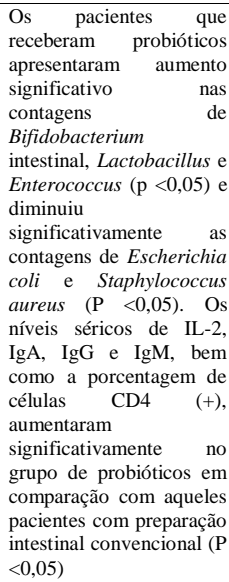 \\
\hline
\end{tabular}

\section{DISCUSSÃO}

Segundo Gianotti et al. ${ }^{20}$ o probiótico é um termo genérico que inclui várias espécies de bactérias. No entanto, as cepas probióticas se diferenciam em seus mecanismos de ação, sobrevivência durante $\mathrm{o}$ trânsito do trato gastrointestinal, modulação do metabolismo intestinal, capacidade para afetar o tipo de resposta 
imune e a concorrência com microbiota e patógenos. Assim, o mesmo propôs avaliar duas cepas diferentes de probióticos, a fim de identificar os pontos positivos identificados por outros estudos, como de Derrien et al. ${ }^{24}$.

Achados científicos demonstram que o consumo de produtos lácteos fermentados pode oferecer possíveis efeitos protetores contra adenomas ou carcinomas do cólon ${ }^{25}$.

De acordo com Zhang et al. ${ }^{15}$ o uso de probióticos fez com que as contagens de bifidobactérias aumentassem significativamente, enquanto as contagens de Escherichia diminuíram significativamente nos dias pós-operatórios. As bifidobactérias são bactérias que compõe a biota intestinal; estas residem no colón e promovem benefícios a saúde de seus hospedeiros. Já as Escherichia são bactérias gram-negativas que quando adquirida de alimentos ou água contaminada causa infecções. Os resultados encontrados por esse autor mostrou que o uso de probióticos minimiza a ocorrência de complicações infecciosas pósoperatória.

Liu et al. ${ }^{16}$ observaram que a utilização de probióticos também melhora a resistência transepitelial , diminuindo a translocação bacteriana, reduzindo as bactérias enteropatogênicas no sangue e aumentando a variedade bacteriana fecal. A recuperação pós-operatória do peristaltismo, a incidência de diarreia e as complicações relacionadas com infecções também foram melhoradas.

Vários estudos avaliaram e apoiaram os benefícios positivos para a manutenção do equilíbrio da microbiota intestinal pelo tratamento de probióticos perioperatórios em pacientes submetidos à cirurgia de câncer colorretal. Segundo Yongzhi et al. ${ }^{17}$ o uso de probióticos também contribuiu para a recuperação da função intestinal, isso foi evidenciado através da produção de flatulos e defecação. Mas é valido ressaltar que os efeitos dos probióticos não dependem apenas da administração desses, mas também da fisiologia do hospedeiro.

Kotzampassi et al. ${ }^{18}$ mostraram que o uso das combinações de probióticos não foram benéficos somente em relação a diminuição das complicações pós-operatórias, mas os resultados refletiram também em relação ao tempo de permanência desses pacientes no hospital.

Alguns estudos surgiram com objetivo de avaliar a qualidade de vida desses pacientes com câncer colorretal. Lee et al. ${ }^{19}$ mostraram o efeito da suplementação de probióticos durante 12 semanas nesses pacientes e observaram que a administração de probióticos diminuiu significativamente a proporção de pacientes que sofrem de sintomas intestinais irritáveis e a sensação de fadiga .Os resultados entre os grupos caso e grupo controle pôde perceber a melhora no bem estar funcional, e qualidade de vida em relação ao câncer .

$\mathrm{O}$ estudo realizado por Gianotti et al. ${ }^{20}$ verificou a avaliação da utilização de dois tipos diferentes de probióticos, com isso o autor verificou que foi possível obter resultados favoráveis ao paciente, como exemplo: a diminuição de enterobactérias e enterococos, contribuindo ainda para a modulação da imunidade local. O estudo ainda abordou que é necessário o conhecimento quanto à interação das cepas probióticas a fim de manifestar o potencial positivo dentro da estratégia terapêutica, bem como da quantidade administrada, uma vez que o estudo encontrou bons resultados para doses elevadas $2 \times 10^{9} \mathrm{UFC} / \mathrm{d}$.

Em contrapartida, o probiótico utilizado para avaliar a eficácia no tratamento em pacientes com o CCR não pontuou de forma positiva no estudo realizado por Stephens e Hewett ${ }^{21}$, onde se verificou que no pós-operatório não foi identificado a redução dos sintomas, porém, houve uma reversão da ileostomia em alça nos pacientes acometidos por uma síndrome da ressecção anterior.

Entretanto, Mego et al. $^{26}$ traz que os probióticos avaliados, auxiliam na prevenção de diarreia em pacientes com câncer colorretal metastático tratados à base de irinotecano quimioterapia. Sugerindo-se que a administração de probióticos é segura no ajuste e poderá conduzir a uma diminuição na incidência e severidade da diarreia, sendo esse também um dos sintomas causados pela síndrome da ressecção anterior.

Conforme o estudo anterior, outro estudo abordou que a administração probiótica perioperatória pode ajudar os pacientes submetidos a cirurgia de ressecção de CCR, obtendo benefícios clínicos a curto prazo, considerando uma recuperação mais rápida da função intestinal e menor incidência de diarreia ${ }^{27}$.

Gao et al. ${ }^{9}$ encontrou em seu estudo benefícios quanto suplementação dos probióticos no tratamento dos pacientes com CCR, de modo que os mesmos alteram de forma positiva a microbiota intestinal por meio do aumento de número de microrganismos benéficos. Desse modo, o autor identificou como confiável a utilização dessa suplementação.

Do mesmo modo, o estudo proposto por Xia et al. ${ }^{22}$ obteve resultados favoráveis para o tratamento de CCR, em que foram obtidas excelentes preparações intestinais em um grupo experimental, bem como, os níveis de expressão de ocludina e IgA de cólon foram significativamente maiores no grupo teste em comparação com os do grupo controle. Sendo também, que o número de pacientes com PCR positivo no grupo experimental foi significativamente menor do que o grupo controle após a operação. Desse modo, foi possível identificar que a preparação intestinal de um dia com probióticos pode manter a 
função de barreira intestinal após a cirurgia de câncer colorretal, que é adequado para cirurgia colorretal efetiva.

Além disso, Denipote et al. ${ }^{12}$ sugerem vários mecanismos de atuação, incluindo o estímulo da resposta imune do hospedeiro (por aumentar a atividade fagocitária, a síntese de IgA e a ativação de linfócitos $\mathrm{T}$ e $\mathrm{B}$ ), alterações qualitativas e/ou quantitativas na microbiota intestinal envolvidas na produção de carcinógenos e de promotores, alteração da atividade metabólica da microbiota intestinal, alteração das condições físico-químicas do cólon com diminuição do $\mathrm{pH}$. Outras evidências também sugerem que os probióticos reduzem a resposta inflamatória alteram a atividade metabólica das bactérias intestinais e reduzem o número de bactérias envolvidas na pró-carcinogênese e na mutagênese.

Contribuindo com os pontos positivos do uso de probióticos, o estudo realizado por Zhu et al. ${ }^{23}$ identificou que com o uso do probiótico teve-se o aumento das bactérias benéficas e diminuição dos agentes antimicrobianos. Diante disso, a aplicação perioperatória de probióticos intestinais para substituir os agentes antimicrobianos intestinais orais pré-operatórios pode efetivamente corrigir o desequilíbrio da flora intestinal e melhorar a função imune de pacientes cirúrgicos com câncer colorretal.

\section{CONCLUSÃO}

Conclui-se que o uso de probióticos mostrou efeitos positivos ao tratamento de pacientes com CCR, trazendo benefícios como: a diminuição de enterobactérias e enterococos, melhora na modulação da imunidade local, melhora dos sintomas intestinais, recuperação da função intestinal, entre outros. Entretanto, é importante destacar que, embora os resultados positivos obtidos em trabalhos com uso de probióticos tenham sido verificados, o número limitado de artigos dificulta a generalização dos achados. Assim, destaca-se a necessidade de futuros estudos de longa duração para elucidar melhor essa relação.

\section{REFERÊNCIAS}

1. Kahouli I, Malhotra M, Westfall S, Alaoui-Jamali MA, Prakash S. Design and validation of an orally administrated active L. fermentum-L. acidophilus probiotic formulation using colorectal cancer Apc Min/+ mouse model. Appl Microbiol Biotechnol. 2017;101(5):1999-2019.

2. Oliveira RC, Rêgo MAV. Mortality risck of colorectal câncer in Brazil from 1980 to 2013. Arq Gastroenterol 2016;53(2)76-83.

3. Instituto Nacional de Câncer (INCA). Tipos de câncer: colorretal. Rio de Janeiro: INCA; 2018.

4. Instituto Nacional de Câncer (INCA). Estimativa 2016: incidência de Câncer no Brasil. Rio de Janeiro: INCA; 2016.
5. Brasil. Ministério da Saúde. Departamento de Informática do SUS (DATASUS). Painel de Monitoramento da Mortalidade CID-10. Brasília; 2017.

6. Corrêa RS, Pinto JRFE, Santos LV, Góis MC, Silva RP, Silva HM. Rectal cancer survival in a Brazilian Cancer Reference Unit. J Coloproctol. 2016;36:203-7.

7. Oliveira AL, Aarestrupo FM. Avaliação nutricional e atividade inflamatória sistêmica de pacientes submetidos à suplementação com simbióticos. ABCD arq bras cir dig. 2012;25(3):147-53.

8. Jacoby JT, Guzzon S, Rosech LFW, Mendes RH. Uso de pré, pró e simbióticos como coadjuvantes no tratamento do câncer colorretal. Clin Biomed Res. 2017;37(3):232-46.

9. Gao Z, Guo B, Gao R, Zhu Q, Wu W, Qin H. Probiotics modify human intestinal mucosaassociated microbiota in patients with colorectal cancer. Mol Med Rep. 2015;12(4):6119-27.

10. Chaves PL, Gorini MI. Qualidade de vida do paciente com câncer colorretal em quimioterapia ambulatorial. Rev Gaucha Enferm. 2011;32(4):767-73.

11.Barbosa, LRLS. Perfil nutricional de pacientes em pré-operatório eletivo para câncer colorretal [dissertação]. Belo Horizonte: Universidade Federal de Minas Gerais; 2011.

12.Denipote FG, Trindade EBSM, Burini RC. Probióticos e Prebióticos na atenção primária ao câncer de cólon. Arq Gastroenterol. 2010;47(1):93-8.

13. Machado FF, Lazzaretti RK, Poziomyck AK. Uso de prebióticos, probióticos e simbióticos nos pré e pós- operatórios do câncer colorretal: uma revisão. Rev bras cancerol. 2014;60(4):363-70.

14.Correia MITD, Liboredo JC, Consoli MLD. The role of probiotics in gastrointestinal surgery. Nutrition. 2012;28(3):230-34.

15.Zhang JW, Du P, Gao J, Yang BR, Fang WJ, Ying CM. Preoperative probiotics decrease postoperative infectious complications of colorectal cancer. Am J Med Sci. 2012;343(3):199-205.

16.Liu Z, Qin H, Yang Z, Xia Y, Liu W, Yang J et al. Randomised clinical trial: the effects of perioperative probiotic treatment on barrier function and postoperative infectious complications in colorectal câncer surgery - a double-blind study. Aliment Pharmacol Ther. 2011;33(1):50-63.

17. Yang Y, Xia Y, Chen H, Hong L, Feng J, Yang J et al. The effect of perioperative probiotics treatment for colorectal cancer: short-term outcomes of a randomized controlled trial. Oncotarget. 7(7);8432-40. 
18. Kotzampassi K, Stavrou G, Damoraki G, Georgitsi M, Basdanis G, Tsaousi G et al. A fourProbiotics regimen reduces postoperative complications after colorectal surgery: a randomized, double-blind, placebo-controlled study. World J Surg. 2015;39(11):2776-83.

19.Lee JY, Chu SH, Jeon JY, Lee MK, Park JH, Lee DC et al. Effects of 12 weeks of probiotic supplementation on quality of life in colorectal cancer survivors: a double-blind, randomized, placebo-controlled trial. Dig Liver Dis. 2014;46(12):1126-32.

20.Gianotti L, Morelli L, Galbiati F, Rocchetti S, Coppola S, Beneduce A. A randomized doubleblind trial on perioperative administration of probiotics in colorectal cancer patients. World $\mathrm{J}$ Gastroenterol. 2010;16(2):167-75.

21.Stephens JH, Hewett PJ. Clinical trial assessing VSL\#3 for the treatment of anterior resection syndrome. ANZ J Surg. 2012;82(6):420-27.

22.Xia Y, Yang Z, Chen HQ, Qin HL. Effect of bowel preparation with probiotics on intestinal barrier after surgery for colorectal cancer. Zhonghua Wei Chang Wai Ke Za Zhi. 2010;13:528-31.

23.Zhu D, Chen X, Wu J, Ju Y, Feng J, Lu G, et al. Effect of perioperative intestinal probiotics on intestinal flora and immune function in patients with colorectal cancer. Nan Fang Yi Ke Da Xue Xue Bao. 2012;32(8):1190-93.

24.Derrien M, Van Hilckama Vlieg JE. Fate, activity, and impact of ingested bacteria within the human gut microbiota. Trends Microbiol. 2015;23(6):354-366.

25.Gaudier E, Michel C, Segain JP, Cherbut C, Hoebler C. The VSL\#3 probiotic mixture modifies microflora but does not heal chronic dextran-sodium sulfateinduced colitis or reinforce the mucus barrier in mice. $J$ Nutr. 2005;135(12):2753-61.

26. Mego M, Chovanec J, Vochyanova-Andrezalova I, Konkolovsky P, Mikulova M, Reckova M et al. Prevention of irinotecan induced diarrhea by probiotics: a randomized double blind, placebo controlled pilot study. Complement Ther Med. 2015;23(3):356-62.

27. Yang Y, Xia Y, Chen H, Hong L, Feng J, Yang J et al. The effect of perioperative probiotics treatment for colorectal cancer: short-term outcomes of a randomized controlled trial. Oncotarget. 2016;7(7):8432-40.
CONFLITO DE INTERESSES

Os autores declaram não haver conflitos de interesse.

\section{AUTOR PARA CORRESPONDENCIA}

\section{Gleyson Moura dos Santos}

g_leyson_moura@hotmail.com

Submetido em 21/08/2018

Aceito em 04/10/2018 